\title{
Cognitive deficits associated with chronic hepatic encephalopathy and their response to levodopa
}

\author{
ALICK ELITHORN ${ }^{1}$, MICHAEL LUNZER, AND JOHN WEINMAN \\ From the Departments of Medicine and Psychological Medicine, Royal Free Hospital, \\ the Unit of Psychology at Guy's Hospital Medical School, \\ and the Institute of Neurology, London
}

SYNOPSIS A battery of computer-based psychological tests given to seven patients with chronic hepatic encephalopathy showed them to be intellectually impaired, particularly on speed-based measures, as compared with general hospital patients and with patients with cirrhosis but without clinical or electroencephalographic evidence of encephalopathy. Two of the seven patients in the latter group also showed evidence of cognitive impairment on some tests. The effects of levodopa were also evaluated by sequential assessment with these tests. Although there was some improvement in speed of performance on certain tasks and a suggestion of deterioration on other measures, there was little overall change. It is concluded that levodopa has an 'arousing' or antidepressant action and that its effect on intellectual functions is secondary to this alerting effect and is consequently dependent on the emotional and attentional status of the patient.

Chronic liver disease may be complicated by a chronic neuropsychiatric syndrome referred to as chronic hepatic (portosystemic) encephalopathy (CHE). Most patients with $\mathrm{CHE}$ have undergone portosystemic shunt surgery for the relief of portal hypertension but a minority develop chronic encephalopathy after the development of a natural shunt (Summerskill et al., 1956). Evaluation of these patients has rarely included intellectual assessment based on objective psychological tests. However, Zeegan et al. (1970a) using a star drawing test and the Reitan's Trail Test reported impairment after portocaval anastomosis. In another study (Zeegan et al., 1970b), the same group tested four patients before and after treatment with lactulose and reported that two patients improved on the Trail Test. However Read et al. (1968) have reported that EEG changes can be used as objective evidence of cerebral involvement and stressed the importance of early diagnosis. They suggested that there might be a latent period in the development of $\mathrm{CHE}$ during which both the

1 Address for reprint requests: Alick Elithorn, Department of Psychological Medicine, Royal Free Hospital, Pond Street, London, N.W.3. (Accepted 14 April 1975.) neurological examination and the EEG are normal.

In the course of evaluating a battery of computer based tests we have carried out a study ono seven patients with established CHE, together with seven 'control' patients with cirrhosis, in whom encephalopathy had been excluded clinically and by EEG, and with a further seven control patients without liver disease. The battery included measures of route-finding, coding, short-term memory, multiple choice, and simple reaction time and motor tapping. Since the item-generation procedures devised for these tasks make them particularly suitable for sequential use (Jones and Weinman, 1973), the performance of four patients undergoing a therapeutic trial of levodopa was monitored.

Levodopa has been shown to produce improvements in cognitive functioning in patients with Parkinsonism, but the nature of these improvements is not clear. Several authors have attributed this improvement entirely to an arousal effect (Cotzias et al., 1969; GodwinAusten et al., 1969; Yahr et al., 1969; Horvarth and Meares, 1974), others report a specific effect on intellectual functions independent of arousal 
(Marsh et al., 1971; Loranger et al., 1972), while yet others have pointed out that the tests used failed to evaluate the motor component in the subjects' performance and hence cannot resolve this issue (Birdsong and McKinney, 1974). The tests reported here use computer techniques to maximize the evaluation of different aspects of performance and in the present paper we also use our findings to interpret the conflicting reports in the literature.

\section{METHODS}

PATIENTS WITH CHRONIC HEPATIC ENCEPHALOPATHY (CHE) This group comprised seven patients, four men and three women aged from 41 to 70 years (mean age: 55.8 years). All these patients had cirrhosis proven by liver biopsy and persistently abnormal EEGs and neurological signs. None of these patients was suffering from alcoholic liver disease, nor were any receiving medication known to affect the central nervous system. Four were subsequently included in a double-blind clinical trial of levodopa (Lunzer et al., 1974).

PATIENTS WITH CIRRHOSIS BUT WITHOUT CLINICAL EVIDENCE OF ENCEPHALOPATHY This group also comprised seven patients, with four men and three women, ranging in age from 37 to 73 years (mean age: 54.1 years). All these patients had cirrhosis proven by liver biopsy, but had never had any EEG or neurological evidence of encephalopathy.

CONTROL PATIENTS Seven hospitalized patients, without liver disease or encephalopathy, formed the control group. There were four men and three women, aged from 41 to 73 years (mean age: 53.6 years).

In addition to being matched for age, the three groups were also fairly closely matched for verbal IQ on the Mill Hill Vocabulary Test, in order to provide some control for premorbid intellectual functioning.

TESTS EMPLOYED A battery of six tests was used in the comparison of the three groups as well as in the serial test situation. The tests were:

1. Motor tapping.

2. Auditory two-choice reaction time.

3. Ten-choice reaction time.

4. Coding: (a) accuracy-stressed, (b) speedstressed.

5. Digit span.

6. Perceptual Maze.
All the tests, which are described more fully elsewhere (Lunzer et al., 1974) were presented on a small computer system using a cathode ray oscilloscope display (Jones and Weinman, 1973).

\section{RESULTS}

COGNITIVE IMPAIRMENT ASSOCIATED WITH CHRONIC HEPATIC ENCEPHALOPATHY Table 1 gives the mean test scores for the three groups of patients. As a group, the patients with $\mathrm{CHE}$ are severely impaired intellectually. On all tests, the mean

\section{TABLE 1}

MEAN AGES AND TEST SCORES OF PATIENTS WITH CHRONIC HEPATIC ENCEPHALOPATHY AND TWO CONTROL GROUPS*

\begin{tabular}{|c|c|c|c|}
\hline & $\begin{array}{c}\text { Patients } \\
\text { with } \\
\text { CHE } \\
(N=7)\end{array}$ & $\begin{array}{l}\text { Non- } \\
\text { encephalopathic } \\
\text { liver } \\
\text { patients } \\
(N=7)\end{array}$ & $\begin{array}{c}\text { Hospital } \\
\text { controls } \\
(N=7)\end{array}$ \\
\hline Age $(y r):$ & 55.8 & 54.1 & 53.6 \\
\hline $\begin{array}{l}\text { a. Mill Hill vocabulary } \\
\text { (percentile) } \\
\text { Visual digit span }\end{array}$ & 54.02 & 61.0 & 58.0 \\
\hline $\begin{array}{c}\text { Fast rate - mean span } \\
\text { Slow rate - mean span } \\
\text { Perceptual Maze row size }\end{array}$ & $\begin{array}{l}4.24 \\
5.02 \\
6.26\end{array}$ & $\begin{array}{l}5.41 \\
5.28 \\
8.47\end{array}$ & $\begin{array}{l}5.35 \\
5.92 \\
7.57\end{array}$ \\
\hline $\begin{array}{l}\text { b. Perceptual Maze } \\
\text { Mean time per node (s) } \\
\text { Auditory } 2 \text { choice reaction }\end{array}$ & 2.13 & 1.13 & 0.93 \\
\hline $\begin{array}{l}\text { time (s) } \\
\text { Visual } 10 \text { choice reaction }\end{array}$ & 0.65 & $\dagger$ & 0.39 \\
\hline $\begin{array}{l}\text { time (s) } \\
\text { Coding }\end{array}$ & $2.04 \ddagger$ & 1.31 & 1.28 \\
\hline $\begin{array}{l}\text { Accuracy (s/item) } \\
\text { Speed (s/item) }\end{array}$ & $\begin{array}{l}6.26 \ddagger \\
5.10 \S\end{array}$ & $\begin{array}{l}3.19 \\
2.92\end{array}$ & $\begin{array}{l}2.89 \\
2.51\end{array}$ \\
\hline Motor tapping (s/tap) & $0.90 \ddagger$ & 0.53 & 0.47 \\
\hline
\end{tabular}

* a. Level measures, in which lower scores indicate an impaired performance. b. Speed measures-that is, higher scores indicate an impaired performance. All scores show mean response times in seconds.

† Results from this test are not included because of technical failure during the recording of three patients.

$\left.\begin{array}{l}\ddagger \mathrm{P}>0.01 \\ \S \mathrm{P}>0.05\end{array}\right\}$ as compared with the normal hospital control group.

scores are lower than those of either of the two other groups. This impairment is most marked on the speed-based measures, nearly all of which show statistically significant impairment. There is a definite impairment on the short-term memory test and a comparison of the scores at the two presentation rates suggests that this effect is 
not due to a failure of concentration, since performance at the slower rates of presentation, which allows for the development of rehearsal strategies, is less impaired than performance at the faster rates.

The individual results show that all seven patients performed outside the range of scores obtained by the control patients on at least one test. Six patients were outside this range in three tests and five on four tests. Of the seven cirrhotic patients in whom the EEG and clinical findings were normal, two showed definite evidence of impaired performance on most of the speedbased measures.

CHANGES ASSOCIATED WITH LEVODOPA TREATMENT Table 2 summarizes the changes that were found with four patients with CHE, who were treated with levodopa. All patients were

\section{TABLE 2}

EFFECTS OF LEVODOPA ON TEST PERFORMANCE IN FOUR PATIENTS WITH CHE*

\begin{tabular}{lll}
\hline & Off drug & on drug \\
\hline a. Digit span & & \\
$\quad$ Fast rate - mean span & 5.00 & 5.37 \\
$\quad$ Slow rate - mean span & 5.93 & 5.28 \\
Perceptual Maze & 7.46 & 6.30 \\
$\quad$ Row size & & \\
b. Perceptual Maze & & \\
$\quad$ Mean time per node (s) & 1.15 & 0.91 \\
$\quad$ Auditory 2 choice reaction time (s) & 0.47 & 0.45 \\
Visual 10 choice reaction time (s) & 1.61 & 1.68 \\
Coding & 3.94 & 4.07 \\
$\quad$ Speed stress (s/item) & 4.69 & 4.11 \\
$\quad$ Accuracy stress (s/item) & 0.82 & 0.82 \\
Motor tapping (s/tap) & & \\
\end{tabular}

* a. Level measures (lower scores indicate an impaired performance) b. Speed measures (higher scores indicate an impaired performance).

treated double-blind and the order of medication was balanced for practice effects-that is, two patients were tested first while on placebo tablets and then during levodopa treatment and two were tested in the reverse order. Overall these four patients did better while on levodopa. They did less well on the tests of memory and attention but showed improved scores on the speed-based tests which require speeded motor coordination. In only two tests' however, did all four patients show improvement. These were the coding tests under the accuracy condition and the auditory reaction time test. Three patients showed improvement on the fast rate digit span test and on the tapping test, one patient showed some impairment on both these tests. It is worth noting that these four tasks, all of which have speed-based aspects, showed considerable differences in these patients as compared with the two control groups. Although drug-related improvements did occur with these tasks, the improved level of performance was still far below that found in the control groups.

In contrast with these scores, two measures of intellectual competence which were relatively speed independent showed evidence of impairment associated with levodopa. On the Perceptual Maze Test all four patients were impaired. Three were impaired on the slow rate digit span test. On the 10-choice reaction time test, which is the speed based test with the highest intellectual loading, the performance of three out of four was again impaired.

\section{DISCUSSION}

CHRONIC HEPATIC ENCEPHALOPATHY AND COGNI TIVE FUNCTIONING The finding that patientso with CHE show marked impairment on as varied battery of psychometric tests is not surprising. More interesting, but perhaps no. more surprising, is the finding that two patients with liver disease in whom an encephalopathy had not been diagnosed, clinically or electroencephalographically, show evidence of intellectual loss on some tests. As Read et al. (1968) have already demonstrated that serial EEGs can provide an early indicator of latent encephalopathy which allows preventive treatment, it follows that suitable psychometric tests will also make a useful contribution to the early detection of cerebral involvement in patients with liver disease.

EFFECTS OF LEVODOPA ON INTELLECTUAL FUNCTIONS The results of this study, although obtained with only a small number of patients, suggest that levodopa has a mixed effect on cognitive skills, some measures showing deterioration and others improvement. This pattern of results does not appear to have been reported in any one study, though the studies 
themselves appear to conflict, some reporting improvement and some deterioration.

Several authors who have reported that patients with Parkinsonism receiving levodopa are able to think faster and more clearly have attributed this to its awakening-alerting effect (Cotzias et al., 1969; Godwin-Austen et al., 1969; Yahr et al., 1969). However, Loranger et al. (1972), on the basis of a carefully carried out study of 40 patients, claimed that levodopa specifically improved intellectual functions, particularly perceptual skills, independently of its effect on mood. Marsh et al. (1971) using a different battery of tests also concluded that levodopa produced specific intellectual enhancement of verbal learning capacity and auditory perception which could not be accounted for by a generalized awakening or alerting. This latter study has recently been criticized by Horvarth and Meares (1974) who reported an increase in arousal with levodopa which they claimed could not be accounted for by a physical improvement or by the relief of depression. Contrasting with these accounts of intellectual improvement, there are also reports that levodopa may actually impair intellectual performance in some patients (Van Woert et al., 1970; O'Brien et al., 1971). Finally Botez and Barbeau (1973) have concluded that levodopa per se does not seem to be involved in the intellectual deterioration observed in Parkinsonism patients after long-term treatment with levodopa. These conflicting opinions might reflect the failure to distinguish specific intellectual changes from those brought about by a general speeding up of cerebral functions or by an increase in motivation, drive or arousal level.

In normally motivated subjects, a further increase in motivation will, in general, facilitate performance on simple psychomotor tasks but tends to impair performance on more complex tasks. This finding has been canonized in contemporary psychology as the Yerkes-Dodson Law (Yerkes and Dodson, 1908).

Computer generated tests allow the control of the timing and duration of stimulus presentation and the accurate timing of subjects' responses and hence make it possible to evaluate the relative contribution made to the test results by the speeding up of specific processes. Thus, although the present results are obtained with only four patients, the findings facilitate the reconciliation of the apparently contradictory results of the more extensive studies. The observation that simple auditory reaction times are speeded and complex reaction times (10 choice) slowed and that the rate of presentation of stimuli determines the results obtained with tests of short term memory, support the 'arousal' hypothesis. This is in fact supported by some of the observations of Marsh et al. (1971)-for example, that memory span for digits forward is increased, while the memory span for reversed digits is impaired. These results, therefore, as well as those of Horvarth and Meares (1974), can be fitted into the model of the effect of arousal in intellectual functions outlined above-that is, they obey the Yerkes-Dodson Law. The findings of Loranger et al. (1972) can also be fitted to this model. These authors report their observations in terms of factor scores rather than in terms of individual test results, and claim that, compared with controls, their patients showed intellectual gains on tests of perceptual organization as did those of Meier and Martin (1970). A close study of their results, however, shows that 16 out of 40 patients showed impairment on one or other of their factor scores. Furthermore, the majority of perceptual tests used in both these studies are speed-based and require manipulative skills which are specifically improved by levodopa. As Birdsong and McKinney (1974) have recently emphasized, these perceptual tests neither evaluate the motor component nor isolate the perceptual component.

It is a little difficult to understand why so many authors have been reluctant to attribute the intellectual improvement which sometimes accompanies levodopa administration to its well-established antidepressant effects. Loranger et al. (1972) reported that $71 \%$ of their patients had been depressed before treatment, while in the study by O'Brien et al. (1971) $75 \%$ of 16 patients showed clinical evidence of depression and of these $58 \%$ became less depressed with treatment. Three patients showed a mild or marked hypomanic reaction. In an interesting study by Kojima and Yasukochi (1973), two out of five patients with organic depressive psychoses developed hypomanic responses. In two recent reviews of computer based tests, developed from those used in the present study, it has been 
reported that in many patients stimulant drugs tend to speed motor responses and slow perceptual and decision processes (Avons et al., 1974; Elithorn, 1974). On the other hand, relief from depression tends to improve all aspects of intellectual skills.

It is therefore possible to conclude from this study and from the literature that levodopa has both an antidepressant and a stimulant effect and that these sometimes produce concomitant improvements in intellectual functions. Furthermore, the apparent impairment of some intellectual functions found both in this study and in studies of Parkinsonism patients could be attributed to the known effects of increased arousal on more complex skills.

M.L. is Watson Smith Fellow of the Royal College of Physicians. We thank Professor S. Sherlock for referring her patients for investigation, Miss J. James for assistance with the testing, and $\mathrm{Mr} \mathrm{A}$. Telford and $\mathrm{Mr} \mathrm{J}$. Powell for technical assistance. Levodopa and placebo were kindly supplied by Dr A. N. Duffus of Roche Pharmaceuticals Ltd, who also provided financial support.

\section{REFERENCES}

Avons, S., Cooper, R., and Elithorn, A. (1974). Daily behavioural analysis of therapeutic change. Proceedings of DECUS (Europe), 1, 149-153.

Birdsong, J. H., and McKinney, A. S. (1974). Long-range motor performance changes in levodopa-treated patients with Parkinson's disease. Neurology (Minneap.), 24, 107115.

Botez, M. I., and Barbeau, A. (1973). Long-term mental changes in levodopa-treated patients. Lancet, 2, 1028-1029.

Cotzias, G. C., Papavasiliou, P. S., and Gellene, R. (1969). Modification of Parkinsonism-chronic treatment with levodopa. New England Journal of Medicine, 280, 337-345.

Elithorn,'A. (1974). Combining inferences from single sequential trials. In proceedings of Nato symposium on Statistical Design of Experimental Field Trials. Edited by A. L. Leese. Nato: Ottawa.
Godwin-Austen, R. B., Tomlinson, E. B., Frears, C. C., and Kok, H. W. L. (1969). Effects of L-dopa in Parkinson's disease. Lancet, 2, 165-168.

Horvarth, T. B., and Meares, R. A. (1974). Levodopa and arousal. Journal of Neurology, Neurosurgery, and Psychiatry, 37, 416-421.

Jones, D., and Weinman, J. (1973). Computer based psychological testing. In Artificial and Human Thinking, pp. 83-93. Edited by A. Elithorn and D. Jones. Elsevier: Amsterdam.

Kojima, H., and Yasukochi, G. (1973). Treatment with levodopa in two cases of organic brain syndrome. Folia Psychiatrica et Neurologica Japonica, 27, 155-166.

Loranger, A. W., Goodell, H., Lee, J. E., and McDowell, F. (1972). Levodopa treatment of Parkinson's syndrome. Archives of General Psychiatry, 26, 163-168.

Lunzer, M., James, I. M., Weinman, J., and Sherlock, S. (1974). Treatment of chronic hepatic encephalopathy with levodopa. Gut, 15, 555-561.

Marsh, G. G., Markham, C. M., and Ansel, R. (1971). Levodopa's awakening effect on patients with Parkinsonism. Journal of Neurology, Neurosurgery, and Psychiatry, 34, 209-218.

Meier, M. J., and Martin, W. E. (1970). Intellectual changes associated with levodopa therapy. Journal of the American Medical Association, 213, 465-466.

O'Brien, C. P., DiGiacomo, J. N., Fahn, S., and Schwarz, G. A. (1971). Mental effects of high-dosage levodopa. Archives of General Psychiatry, 24, 61-64.

Read, A. E., McCarthy, C. F., Ajdukiewicz, A. B., and Brown, G. J. A. (1968). Encephalopathy after portocavato $\infty$ anastomosis. Lancet, 2, 999-10001.

Summerskill, W. H. J., Davidson, E. A., Sherlock, S., anष्ठ Steiner, R. E. (1956). The neuropsychiatric syndrome associated with hepatic cirrhosis and an extensive porta马 collateral circulation. Quarterly Journal of Medicine, 25 245-266.

Van Woert, H. H., Heninger, G., Rathey, U., and Bowers M. B. (1970). Levodopa in senile dementia. Lancet, 1, 573를 574.

Yahr, M. D., Duvoisin, R. C., Schear, M. J., Barrett, R. Eç仓 and Hoehn, M. H. (1969). Treatment of Parkinsonism ${ }^{+}$ with levodopa. Archives of Neurology, 21, 343-354.

Yerkes, R. M., and Dodson, J. D. (1908). The relation of strength of stimulus to rapidity of habit-formation. Journal of Comparative Neurology and Psychology, 18, 459-482.

Zeegan, R., Drinkwater, J. E., and Dawson, A. M. (1970a). Method for measuring cerebral dysfunction in patients with liver disease. British Medical Journal, 2, 633-636.

Zeegan, R., Drinkwater, J. E., Fenton, J. C. B., Vince, A., and Dawson, A. M. (1970b). Some observations on the effect of treatment with lactulose on patients with chronic hepatic encephalopathy. Quarterly Journal of Medicine, 39, 245-263. 